\title{
Study on Optimal Spatial Allocation between Tourism Industry and Subject-The case of Yunnan province
}

\author{
Qi Wang ${ }^{1}$, Mu Zhang ${ }^{1} \&$ Jing Luo ${ }^{1}$ \\ ${ }^{1}$ Shenzhen Tourism college, Jinan University, Shenzhen, Guangdong, China \\ Correspondence: Jing Luo, Shenzhen Tourism college, Jinan University, Overseas China Town, Nanshan \\ District, Shenzhen, Guangdong, 518053, China. Tel: 86-189-3807-5050. E-mail: ivyluojing@163.com
}

Received: July 28, 2016

Accepted: August 15, 2016

Online Published: November 1, 2016

doi:10.5539/hes.v6n4p81

URL: http://dx.doi.org/10.5539/hes.v6n4p81

\begin{abstract}
There exists mutual improvement and restriction between regional tourism industry and the development of the tourism subject. With the rapid development of the tourism industry, it has set up the tourism program in the universities of Yunnan Province. However, the regional development of the construction of tourism subject is not balanced and its construction is still at the primary stage. Therefore, in spatial dimension, the method of principal components analysis is firstly adopted to construct comprehensive evaluation index system of the tourism development and subject construction. According to the results of the evaluation and analysis, the authors have ranked and classified 16 cities in Yunan province and summarized 5 synchronous development types of the tourism subject and industry. Finally, according to the different regions, the authors have proposed the different modes of subject construction and the strategies of optimal allocation.
\end{abstract}

Keywords: tourism industry, tourism subject, spatial distribution, optimal allocation, Yunnan province

\section{Introduction}

In 2009, "the opinion of the State Council on the development of tourism industry" was officially issued. Its core idea is to foster tourism as a national economical strategic backbone and people's favorable modern service industry which indicates that tourism industry has grown as national strategic system with the positive acknowledgement of tourism's significant status in economic and social development.

According to the predication of "the $11^{\text {th }}$ five-year" planning guidance of tourism industry, there will increase 500 thousand tourism staff every year, among them, 224 thousand tourism talents will offer broad platform for tourism education. Therefore, this paper will choose tourism subject as the object, attempt to solve the problem of spatial arrangement and development scale of tourism major in college of Yunnan province. Since tourism colleges and industry concern much about undergraduate education of tourism subject, the research on predication of spatial allocation and development scale is expected to supply strategic support on rational allocation and development for education Bureau of Yunan government.

\section{Literature Review}

As tourism industry is dominant by government for years in China, there witnesses a growing tendency after Beijing Olympic Games, and more colleges set up tourism programmes. Therefore, Liu Jiao thought it was sustainable to achieve mutual development of tourism education and industry. However, tourism education lags behind the time, government, industry and scholars have to take the responsibility to improve it (Liu, 2014). What's more, some scholars tried to construct index system to evaluate tourism development situation, for example, Yi, Zhang set up an evaluation index system for regional tourism development potential with factor analysis and cluster analysis etc., they conducted static evaluation and analysis on tourism development potential in all provinces of China in 2009 (Yi \& Zhang, 2012). An Yingmin and Liu Ting took time and spatial analysis on regional tourism development by WPC TOPSIS value function model (Yingmin \& Liu, 2013). While Wang empirically studied spatial difference characteristics of human resource investment to regional tourism industry development influence to discuss the reason of regional tourism industry development difference by provincial panel data model (Wang, 2014). Tang discussed tourism development difference by variation coefficient, Geordie coefficient in the aspects of production elements, tourism elements investment and tourism income etc. (Tang, 2010). Though Chinese and foreign scholars have had some research on the relationship between tourism 
higher education and regional tourism development, there is a huge difference in research direction and method. Study abroad focuses on establishing tourism education system by analyzing the relationship between tourism education and industry. Jennifer and Michael discussed the relationship between tourism industry and its education and then proposed to combine traditional economical subject with geography in tourism education (Jennifer \& Michael, 2002). Paul had a review on British tourism education development based on tourism industry growth (Paul, 2010). Kellee addressed the present situation of tourism higher education in the settings of "new-liberalism university", he thought there were mutual benefit of tourism education and its industry, but eventually it would be favorable to students' capacity (Kellee, 2014). Fabio Zagonari insisted the balance of tourism education and training could benefit tourism stakeholders (Fabio, 2009). While most Chinese studies concerned more about tourism subject construction. For example, Zhang thought the system construction and subject development of tourism should accord with the most basic and core conception (Zhang, 2012). Lv and Liu held the idea that tourism industry development was one of the major elements for tourism education development, but it was also affected by national education development policy (Lv \& Liu, 2009). In conclusion, according to the literature review, there are barely studies involving tourism spatial arrangement and subject development prediction, though some scholars have done some researches on tourism higher education, few Chinese scholars can be found. Hence, authors think it is very necessary to set up a tourism subject system combining with regional tourism development.

\section{The Spatial Allocation between Tourism Development and Tourism Subject in Yunnan Province}

\subsection{Development of Tourism Industry}

Growing from 1980's, tourism development in Yunnan province experiences a boom in tourism development by seizing the opportunity of the policy of "Western Development", the event of "International Horticultural Exposition 1999 Kunming China". The statistic of 2010 indicates that the total income of tourism in Yunnan province has reached 100.68 billion Yuan, and it is the first time of reaching the breakthrough in hundred billion Yuan. And all the indexes in 2005 have been doubled, which makes Yunnan a genuine tourism province.

Yunnan province boasts its rich tourism resource with various spatial allocation. Early in 2006, Yunnan government issued "Overall Planning of Yunnan tourism development (2001-2010)", "the Tenth five years' development plan of tourism in Yunnan", "Regional development plan of six tourism regions". According to features of resource in scenic spot, it can be divided into six regions (See Table 1).

Table 1. Tourism regions in Yunnan province

\begin{tabular}{|c|c|c|c|}
\hline & Tourism region & location & tour product \\
\hline 1 & $\begin{array}{l}\text { International tour zone of Grand } \\
\text { Kunming in the middle of } \\
\text { Yunnan (Central zone) }\end{array}$ & $\begin{array}{l}\text { Three cities and areas including } \\
\text { Kunming, Yuxi and Chuxiong }\end{array}$ & $\begin{array}{l}\text { Based on eco-tourism, nationality tour and } \\
\text { rural tour, people develop leisure tour, tour for } \\
\text { health and MICE tour etc. }\end{array}$ \\
\hline 2 & $\begin{array}{l}\text { Shangrila tour zone in the west of } \\
\text { Yunnan Province }\end{array}$ & $\begin{array}{l}\text { Four cities and areas including } \\
\text { Dali, Lijing, Diqing and Nujing }\end{array}$ & $\begin{array}{l}\text { They are famous for world natural heritage, } \\
\text { historical place of interests and the product } \\
\text { mainly indicates nationality culture, natural } \\
\text { beauty }\end{array}$ \\
\hline 3 & $\begin{array}{l}\text { Karst mountain and water culture } \\
\text { tour zone in southeast of } \\
\text { Yunnan province }\end{array}$ & $\begin{array}{l}\text { It includes two prefectures such } \\
\text { as Honghe and Wenshan, south } \\
\text { of Qujing, Shilin county of } \\
\text { Kunming }\end{array}$ & $\begin{array}{l}\text { Travel activity and products include rural } \\
\text { scenery, nationality culture, rural tour and } \\
\text { border tour }\end{array}$ \\
\hline 4 & $\begin{array}{l}\text { International tour zone along } \\
\text { Lancang rive and Meigong river }\end{array}$ & $\begin{array}{l}\text { Three regions include } \\
\text { Xishangbanna, Puer and } \\
\text { Lincang }\end{array}$ & $\begin{array}{l}\text { Ecological tour, transnational travel, } \\
\text { nationality travel, hydropower industry travel }\end{array}$ \\
\hline 5 & $\begin{array}{l}\text { Volcano and hot sea border tour } \\
\text { in the west of Yunnan Province }\end{array}$ & $\begin{array}{l}\text { Two prefectures include } \\
\text { Baoshan and Dehong }\end{array}$ & $\begin{array}{l}\text { Health and leisure tour product include Hot } \\
\text { spring tour and ecological tour. Transnational } \\
\text { tour products contain ethnic customs, frontier } \\
\text { culture, jewelry shopping and border tour }\end{array}$ \\
\hline 6 & $\begin{array}{l}\text { Laterite plateau tour zone in } \\
\text { northeast of Yunnan province }\end{array}$ & $\begin{array}{l}\text { It includes Shaotong city, } \\
\text { Dongchuan district of Kunming } \\
\text { and north district of Qujing }\end{array}$ & $\begin{array}{l}\text { Eco-tour, Hot-spring tour, urban leisure, cool } \\
\text { summer tour, river drifting, self-driving tour }\end{array}$ \\
\hline
\end{tabular}


Though travel resource of Yunnan province mainly locates in the middle, northeast and southwest of the province, main part of visitors will go to the areas with advanced economic development, favorable reputation, and well-equipped travel infrastructure such as the city of Xishuangbanna, Dehong, Yuxi, Dali and Lijiang. What's more, with rapid development of tourism industry, there sets up the major of tourism management from key university to regular college, but it seems that it still fails to solve the problem of hand shortage in tourism sector, especially the experts on cross-cultural communication and management.

\subsection{Construction of Tourism Subject and Spatial Allocation Feature}

The statistics from "Enrollment Guidance of higher education in Yunnan Province" indicates that there are 13 colleges or universities of 16 areas or cities set up majors of tourism management in 2009 (See Chart 3-2). Among them, it includes key universities such as Yunnan university, Yunnan Normal University, it also contains some local colleges such as Chuxiong Normal University, Dali University and so on. Expect being rooted in the subject of management, some colleges set it up based on geography, foreign language, economy and ecology etc. In 2009, the number of universities of Yunnan Province increases by 1.17 comparing with that of in the year of 2000. There are 9 colleges locating in Kunming, but only 4 colleges in other 15 areas, which is $30.77 \%$ of the total. It shows that there exists big regional gap on quantity of university in Yunnan Province.

Table 2. University with tourism subject on Bachelor degree in Yunnan Province

\begin{tabular}{cccc}
\hline Name & Location & Name & Location \\
\hline Yunnan University & Kunming & Chuxiong Normal University & Chuxiong \\
Yunnan Normal university & Kunming & Dali University & Dali \\
Yunnan Minzu University & Kunming & Yuxi Normal University & Yuxi \\
$\begin{array}{c}\text { Yunnan University of Finance } \\
\text { and Economics }\end{array}$ & Kunming & Independent college & Lijiang \\
$\begin{array}{c}\text { Yunnan Agricultural } \\
\text { University }\end{array}$ & Kunming & Tourism and culture college, Yunnan university & Kunming \\
Southwest forestry University & Kunming & The college of arts and Science Yunnan normal & university \\
Kunming University & Kunming & Yunnan Normal university business school & Kunming \\
\hline
\end{tabular}

\subsection{Analysis of Time-Space Consistency of Tourism Industry and Subject}

Time-space consistency of tourism industry and subject refers to the degree of positive interaction between tourism undergraduate education and regional tourism industry based on different educational situations and development demands from subject construction, talents fostering and scientific research outcome etc. Therefore, this article will discuss the relationship between tourism subject construction and tourism industry in Yunnan Province. The authors proposed the following three hypothesizes as follows.

Hypotheses One: the larger tourism economic aggregate, the bigger the scale of tourism subject construction;

Hypothesis Two: the better tourism industry performance, the higher quality of tourism education;

Hypothesis Three: the faster tourism industry growth, the quicker the tourism allocation and development speed.

The authors conduct relevance analysis on tourism education development and industry growth in time dimension with statistics of Yunnan's tourism subject and tourism industry. The result indicates that Yunnan has experienced a fast development in tourism industry and education since 2000. There is an increasing tendency in tourism school and enrollment, but there might be some fluctuation for different education conditions, it could still fully prove that all the hypothesizes are workable in the research. As the differentiation in tourism resource, development degree and tourism growth among different places, it is quite necessary to have further study on the relationship in tourism industry and subject in various places. 


\section{Evaluation Index System of Tourism Development}

\subsection{Set up Comprehensive Evaluation Index System}

A comprehensive index system is required for measuring regional development level. Some people address various index weights with hierarchy analysis; some assess and analyze regional tourism competitiveness with the factors such as scale competitiveness, marketing competitiveness, and enterprise competitiveness. While others apply core attraction, basic factor, supportive factor and development factor to evaluate and analyze urban tourism competitiveness. Hence, the authors choose 7 relevant indexes as assessed objects (See Table 4), and then they process various indexes involving tourism development with statistics analysis software. After the validity and efficiency assessment on original statistics, the result indicates that factor analysis could be firstly used, and principal component analysis could be applied to extract principal component to eventually attain eigenvalue and contribution rate of the first three principal components (See Table 3).

Table 3. Factor eigenvalue, attribution rate and accumulative contribution rate of tourism development level

\begin{tabular}{cccc}
\hline $\begin{array}{c}\text { principal } \\
\text { component }\end{array}$ & Eigen value & contribution rate\% & Accumulative contribution value \\
\hline 1 & 3.675 & 52.501 & 52.501 \\
2 & 1.744 & 24.919 & 77.419 \\
3 & .963 & 13.764 & 91.184 \\
& & Extra method: Principal Analysis \\
\hline
\end{tabular}

Finally, it works out factor variance contribution rate from factor model after the factor's maximal rotation to get 3 secondary indexes and 7 third-class assessment index system of regional tourism development level (See Table 4).

Table 4. Integrated assessment index of regional tourism development level

\begin{tabular}{|c|c|c|c|c|}
\hline First Index & Second Index & Third-class Index & Unit & Symbo \\
\hline \multirow{7}{*}{$\begin{array}{l}\text { Development } \\
\text { level of tourism } \\
\text { industry }\end{array}$} & & Added value of tourism income & 10 thousand Yuan & $\mathrm{X} 1$ \\
\hline & Development scale & Added value of visitor & 10 thousand Yuan & $\mathrm{X} 2$ \\
\hline & & Proportion of GDP in tourism income & $\%$ & $\mathrm{X} 3$ \\
\hline & Development & $\begin{array}{l}\text { Contribution rate of tourism added } \\
\text { value to GDP added value }\end{array}$ & $\%$ & $\mathrm{X} 4$ \\
\hline & benefit & $\begin{array}{l}\text { Per Capita added value of tourism } \\
\text { industry }\end{array}$ & Yuan/person & $\mathrm{X} 5$ \\
\hline & & tourism production rate & Yuan/Person & X6 \\
\hline & Development speed & $\begin{array}{l}\text { Increase rate of tourism economic } \\
\text { aggregate increase rate }\end{array}$ & $\%$ & $\mathrm{X} 7$ \\
\hline
\end{tabular}

\subsubsection{Calculation Assessment Index}

According to above index system, the authors attain data from "Statistical Annual of Yunnan" and process statistics of tourism development in all parts of Yunnan province in 2009, they got and sorted three principal component scores and comprehensive scores on tourism development in 16 cities, prefectures and districts of Yunnan province (See Table 5).

Table 5. Score and rank of places in Yunan

\begin{tabular}{ccccccccc}
\hline rank & \multirow{2}{*}{ F1 score (scale) } & \multicolumn{2}{c}{ F2 score (benefit) } & \multicolumn{2}{c}{ F3score (speed) } & \multicolumn{2}{c}{$\begin{array}{c}\text { Comprehensive score of } \\
\text { tourism development level }\end{array}$} \\
\hline $\mathbf{1}$ & Xishuangbannan & 4.48 & Kunming & 3.54 & Puer & 1.48 & Xishuangbannan & 3.51 \\
$\mathbf{2}$ & Lijing & 3.01 & Dali & 1.15 & Yuxi & 1.11 & Lijiang & 1.78 \\
\hline
\end{tabular}




\begin{tabular}{lcccccccc}
\hline $\mathbf{3}$ & Diqing & 2.79 & Yuxi & 1.01 & Wenshan & 1.07 & Kunming & 1.42 \\
$\mathbf{4}$ & Dali & 0.98 & Chuxiong & 0.87 & Shaotong & 1.04 & Dali & 1.21 \\
$\mathbf{5}$ & Kunming & 0.29 & Honghe & 0.61 & Xishuangbannan & 1.03 & Yuxi & 0.84 \\
$\mathbf{6}$ & Yuxi & -0.11 & Lijiang & 0.07 & Chuxiong & 0.66 & Diqing & 0.47 \\
$\mathbf{7}$ & Wenshan & -0.42 & Puer & -0.04 & Baoshan & 0.08 & Chuxiong & 0.11 \\
8 & Honghe & -0.6 & Shaotong & -0.07 & Honghe & 0.01 & Puer & -0.08 \\
9 & Dehong & -0.61 & Xishuangbanna & -0.23 & Qujing & -0.01 & Honghe & -0.13 \\
10 & Chuxiong & -0.78 & Qujing & -0.24 & Dali & -0.18 & Wenshan & -0.16 \\
11 & Puer & -0.84 & Wenshan & -0.52 & Lincang & -0.64 & Shaotong & -0.38 \\
12 & Shaotong & -1 & Baoshan & -0.66 & Dehong & -0.75 & Dehong & -1.15 \\
13 & Baoshan & -1.19 & Dehong & -0.86 & Diqing & -0.8 & Baoshan & -1.16 \\
14 & Qujing & -1.45 & Lincang & -0.9 & Lijing & -1.17 & Qujing & -1.17 \\
15 & Lincang & -2.14 & Nujiang & -1.22 & Nujiang & -1.41 & Lincang & -2.23 \\
16 & Nujiang & -2.41 & Diqing & -2.51 & Kunming & -1.52 & Nujiang & -2.88 \\
\hline
\end{tabular}

Data source: Statistical Annual of Yunnan Province 2008-2010.

Table 5 indicates that the places where tourism plays a great role in GDP include Xishuangbanna, Lijing, Diqing, which mainly locate in the south and northwest of Yunnan, their average core is 3.4267. What's more, there is a rapid growth in tourism income and number of visitor in the city of Kunming, Dali and Yuxi. While in terms of development speed, Puer, Yuxi and Wenshan enjoy a favorable situation. But Diqing, as a city with tourism as the main characteristics, its development is slow for the big cardinal number. Some tour attractions with long history such as Kunming, Lijing and Diqing expect new tourism resource development to stimulate its growth.

\subsubsection{Evaluation of Tourism Subject Establishment}

The authors first classify universities and colleges into three categories by means of subject construction scale. The first class refers to the advanced area, only one city, Kunming, has 9 universities and colleges. The second class is underdeveloped area including four cities such as Yuxi, Lijiang, Chuxiong and Dali. There is only one university or college set up tourism subject. The third class, backward areas contain 13 prefectures and cities without tourism subject in higher education. So it is concluded that there not only exists large difference in quantity, there are also many weaknesses in subject scale in Yunnan Province. Then the authors will have further study on relative quantity:

Being similar with the measurement of tourism development level, this study chooses 3 secondary indexes and 5 third-class evaluation indexes in perspective of subject construction scale, education quality and development speed (See table 6).

Table 6. Comprehensive evaluation index of regional tourism subject construction

\begin{tabular}{lllrc}
\hline \multicolumn{1}{c}{ First Index } & Secondary Index & & Third-class Index & Unit \\
\hline & Development & number of student & person & X1 \\
Comprehensive & scale & number of university & N/A & Xerson \\
$\begin{array}{l}\text { evaluation of } \\
\text { tourism subject } \\
\text { construction }\end{array}$ & Education quality & Number of students per thousand people & N/A & X4 \\
& Development & increment of tourism university & person & X5 \\
\hline
\end{tabular}


It got eigenvalue and contribution rate of a principal component by principal analysis (See table 7).

Table 7. Factor eigenvalue, contribution rate and accumulative contribution ration of tourism subject construction evaluation

\begin{tabular}{cccc}
\hline principal component & Eigenvalue & Contribution rate (\%) & Accumulative contribution rate (\%) \\
\hline 1 & 4.752 & 95.032 & 95.032 \\
& \multicolumn{3}{c}{ Extract method: principal analysis } \\
\hline
\end{tabular}

Therefore, we choose this principal component as comprehensive evaluation index of regional tourism subject construction to get the final score. See Table 8 as follows.

Table 8. Score and ranking in all places

\begin{tabular}{ccc}
\hline Region & Score & Ranking \\
\hline Kunming & 3.37 & 1 \\
Lijing & 0.74 & 2 \\
Yuxi & 0.37 & 3 \\
Dali & 0.24 & 4 \\
Chuxiong & 0.15 & 5 \\
Qujing & -0.44 & 6 \\
Baoshan & -0.44 & 7 \\
Shaotong & -0.44 & 8 \\
Puer & -0.44 & 9 \\
Lincang & -0.44 & 10 \\
Honghe & -0.44 & 11 \\
Wenshan & -0.44 & 12 \\
Xishuangbanna & -0.44 & 13 \\
Dehong & -0.44 & 14 \\
Nujiang & -0.44 & 15 \\
Diqing & -0.44 & 16 \\
\hline
\end{tabular}

Data source: "the Guidance of higher education enrollment of Yunnan" and interview material.

The above results indicate that the allocation of tourism subject in Yunnan province holds great difference in quantity analysis, it also shows the same outcome in constructed subject construction system. So whether there is some connection between subject construction and economic development is the priority to be studied.

\subsection{Verification on Relationship and Outcome of Tourism Industry and Tourism Subject Construction}

\subsubsection{Choice of Relation Model}

As for higher education and regional economic allocation, many scholars have done relevant research with various tools. For example, Professor Sheng proposed the idea to describe degree region allocation by nine palaces graph. Hence, the authors use it for reference to trisect tourism principle construction and tourism development level and classify it into 9 regions. Then the authors will fill the compared and ranked scores of tourism industry development and tourism subject construction level of 2009 in Yunnan into following graph (See Figure 1). 


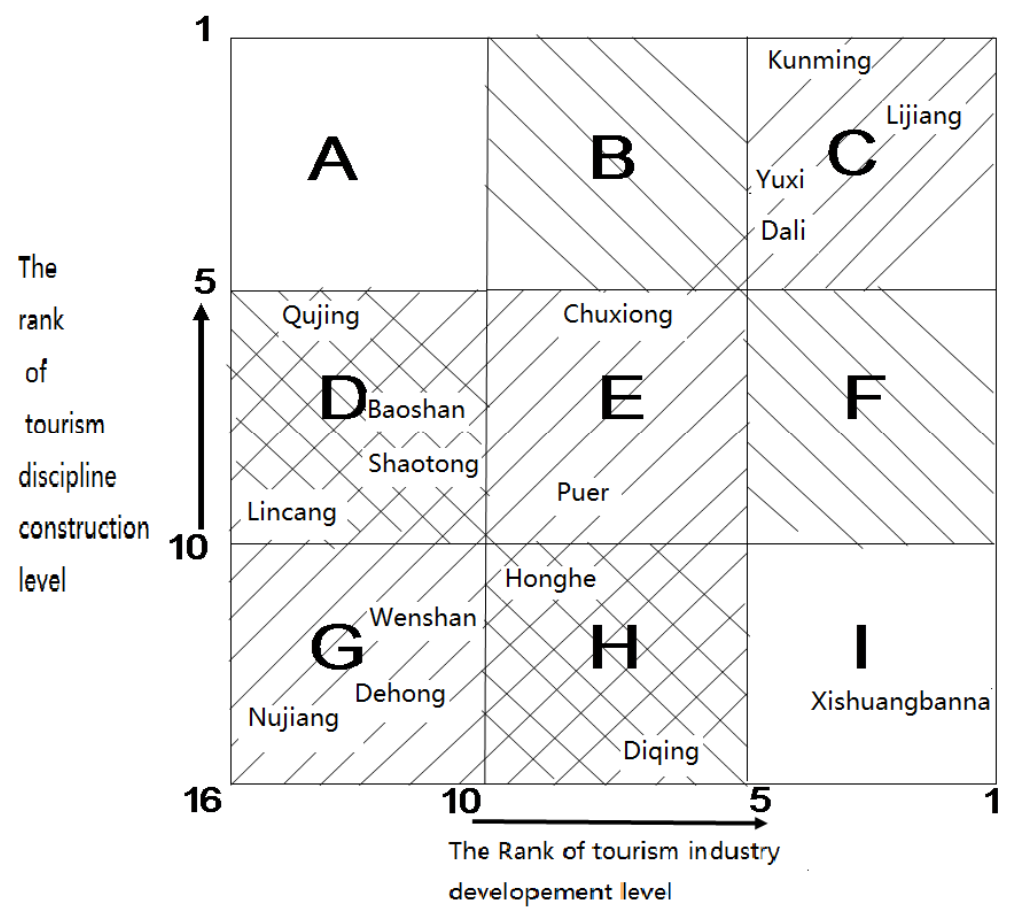

Figure 1. Relationship between tourism development and tourism subject construction of Yunnan province

\subsubsection{Outcome Analysis}

Based on Figure 1, we verify the above three hypothesis, the results are as follows:

(1) Area $\mathrm{C}$ holds the high consistency with tourism development and tourism subject construction. Tourism develops well in this area which promotes further growth of tourism subject construction, and it will also strengthen tourism growth, so they interact favorably. However, there is a great gap for the subject in different areas. For example, in city of Kunming and Lijiang, people can find consistency in allocation and scale in tourism subject allocation and tourism development. While to Yuxi and Dali, their tourism higher education seems fail to satisfy demand of tourism development.

(2) Area E belongs to medium consistent zone of tourism development and tourism subject construction. Two cities in this zone, Chuxiong and Puer, are at the medium stage of development in tourism and its subject construction with a favorable interaction.

(3) It is found that area D is poor at coordination in tourism development and tourism subject construction. Though it is potential in tourism subject construction in the medium status, tourism development is backward. There are universities with bachelor degree in 4 cities in this area, but no tourism major here. Therefore, the supportive role of tourism is barely found here. The city of Qujing, Baoshan and Shaotong are the examples.

(4) The levels of tourism subject construction in area I and H lag behind the average. However, there is a big difference among various places. In recent years, tourism undergraduate education and per capita growth has got progress in Honghe district of $\mathrm{H}$ area. While I area is regarded as the blank place on relationship between tourism development and subject construction. Tourism development level in Xishuangbanna grows far more quickly than tourism subject construction level. So it is required to improve tourism undergraduate education to meet the satisfaction from the tourism-oriented places.

(5) $\mathrm{G}$ area is ranked as the low coordination zone on tourism development and subject construction. Three cities are slow at tourism development and subject construction with poor interaction.

According to the analysis of these six areas, it is found the unbalanced situation in geographical distribution of tourism subject. It mainly involves three situations: 
(1) In terms of tourism development level, slow development in tourism subject is noticed. For example, Dali in $\mathrm{C}$ area and Chuxiong in $\mathrm{E}$.

(2) The potential of tourism subject construction is far ahead of tourism development level, such as the cities in $\mathrm{D}$ area.

(3) The performance in tourism subject construction is poor. For instance, Xishuangbanna in I area, prefecture of Honghe, Wenshan and Diqing in $\mathrm{H}$ area.

\section{Optimized Allocation of Tourism Subject Development in Yunnan Province}

\subsection{Leading Model in Middle Zone of Yunnan Province}

As the middle zone of Yunnan province witnesses a mature growth in tourism industry, there is an improved tourism market system, tourism subject enjoys a big and favorable foundation, so it is a crucial issue to improve subject level and talents education quality. Firstly, all the universities should strengthen school operation regularization and subject building evaluation. According to the change of demand and supply form talents market, some repeated-set and over-set tourism subject could be integrated and reduced so as to guarantee the quality of tourism talents education. Secondly, it is necessary to equip teaching staff with theory knowledge and practical ability by creating an opportunity of a temporary official post for them to increase working experience. What's more, recruiting professionals is another good idea. Cooperating with the universities and organization from China and broad is also a wise way to encourage teacher to work in tourism agency or study in the organization to improve work and research capacity to cultivate the leaders of tourism education.

\subsection{Interactive Model in Northwest Zone of Yunnan Province}

In the prefectures of Nujing and Diqing where tourism develops fast whilst tourism higher education is poor, government should offer more favorable policy to attract creative talents and excellent staff working here to enhance education there. Moreover, regional interaction and cooperation should be highly encouraged. Middle zone with better base could stimulate the development of northwest zone where the subject building is poor but tourism resource is rich. A good example is Lijiang government, who works with Yunnan university to set up Tourism and culture college, Yunnan university, the independent college, there fosters many excellent tourism talents. Hence, it helps to realize the target of increasing tourism college allocation, it can also share qualify subject resource by inter-regional cooperation to enhance local tourism subject building level and capacity to serve local tourism development.

\subsection{Subject Improvement Model in North-East and South-East of Yunnan Province}

Adjustment of tourism college arrangement of Yunnan province should focus on the middle, small city or county city. Because it is not good for regional balanced development as tourism higher education mainly locates in the small number of big cities. As future tourism subject structure and allocation adjustment, it is recommended helping normal university to set up Tourism College, for example, setting up tourism program with existing resource from Qujing normal college. Meanwhile, we can take Yunnan normal university with completed subject system as the reference to build tourism education to eventually foster adequate tourism management talents.

\subsection{New Model in East and West of Yunnan Province}

Though tourism industry develops well, there is no higher education around this area. Especially, the prefecture of Xishuangbanna is in urgent demand of tourism talents to meet the satisfaction of rapid development. Hence, it should focus on fostering preliminary and middle level of tourism talents whose practical skill should be strengthened. Its education target should be set as "application-and-entrepreneur-oriented" talents. During the process of expansion on talents education and tourism subject, we should be patient and far-sighted to avoid the appearance of some inequality university. The backward districts should be given five to ten years to catch up with the advance district to realize the consistent development of tourism economy of Yunnan province.

\section{Conclusion}

As the close relationship between tourism subject construction and tourism development, taking time as the latitude, tourism education and tourism industry in Yunnan province actively interact and grow quickly. However, their relevance is not noticeable in specific tourism district. Except the capital, Kunming, other places turns out the great inconsistency. Therefore, based on the geographical classification, the authors try to work out the relationship graph between tourism development and tourism subject of Yunnan province by investigation and analysis of present situation of tourism industry and subject construction. In terms of geographical region, northwest of Yunnan starts tourism early with more advanced tourism development level. So far, only Lijiang sets up Tourism and Culture college of Yunnan university, so the sharing and interaction model of tourism 
education resource is proper for this place. Northeast and southeast district can make full use of existing normal colleges to increase tourism subject to foster tourism talents. What's more, the west and southwest of Yunnan province which has good location, advanced development of tourism but poor tourism education, it is recommended setting up tourism college and teach application-oriented talents for local tourism sector and adopt the re-training model for tourism staff. Higher education on tourism requires enhancement of service quality and tourism management level, only reasonable tourism subject establishment could motivate growth of tourism industry. In addition, other provinces and cities could make relevance analysis by referring to the evaluation system of tourism industry and subject proposed by the authors. In terms of space and time, it is suggested adopting proper tourism education model according to different development level and stage in different places to achieve coordinative growth of tourism industry and tourism subject.

\section{Acknowledgments}

This paper is a part of the outcome of scientific plan for Young and Creative talents in higher education supported by Education Department of Guangdong province "study on training scheme of ecological literacy for residents in tourism destination" (2012WYM_0023).

\section{References}

An, Y. M., \& Liu, T. (2013). Time and space difference and change study on regional tourism development in China. Forum of West Economy Management, 4, 57-64.

Fabio, Z. (2009). Balancing tourism education and training. International Journal of Hospitality Management, 28, 2-9. http://dx.doi.org/10.1016/j.ijhm.2008.03.006

Jennifer, C., \& Michael, R. (2002). Tourism occupations and education: An exploration study. International Journal of Tourism Research, 4(2), 77-86. http://dx.doi.org/10.1002/jtr.361

Kellee, C. (2014). Underdisciplinarity: Where are the humanities in tourism education? Journal of Hospitality, Leisure, Sport \& Tourism Education, 15(9), 24-33.

Liu, J. (2014). Re-cognition of tourism status in university in present tourism development. Modern Economic information, 9, 450-456.

Lv, L., \& Liu, Y. (2009). Time and space relevance analysis on tourism education and tourism industry development. Agricultural Higher Education, 8, 17-21.

Paul, R. F. (2010). Tourism education and curriculum design: A time for consolidation and review? Tourism Management, 31, 699-723. http://dx.doi.org/10.1016/j.tourman.2010.05.019

Sheng, S. (2007). The speech and degree authorization and audit Conference on reform scheme of Ph.D and Master granting. Nanjing.

Tang, X. (2010). Regional difference study on tourism economic development of China in perspective of production element. Economic Geography, 10, 1741-1745.

Wang, Z. F. (2014). Regional difference study on human resource investment and tourism industry development. Finance Theory and Practice, 1, 132-136.

Yi, Y. F., \& Zhang, Y. J. (2012). Evaluation model and empirical study on regional tourism development potential. Ecological Economy (Academic version), 2, 178-182.

Zhang, L. Y. (2012). Study on tourism research and subject establishment. Tourism Science, 1, 13-25.

\section{Copyrights}

Copyright for this article is retained by the author(s), with first publication rights granted to the journal.

This is an open-access article distributed under the terms and conditions of the Creative Commons Attribution license (http://creativecommons.org/licenses/by/4.0/). 